\title{
Association between air temperature and deaths due to cancer and heart disease in Alabama
}

John Hart

Correspondence: jhartdc@yahoo.com

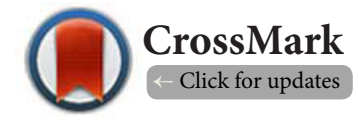

Greenville, South Carolina 29615, USA.

\begin{abstract}
Background: Adverse health effects have been predicted from a so-called "global warming". The present study is the second in a series that tests the global warming question at the county level in an individual state using an ecological design. The state studied this time is Alabama.

Methods: Two response variables, cancer death rates and heart disease death rates for the counties were compared to two environmental "dose" (predictor) variables: air temperature and land elevation.

Results: Linear multiple regression did not reveal any statistically significant adverse health effects for either predictor with these response variables. Indeed, in the heart disease model, warmer temperatures were associated with lower death rates.

Conclusion: These results contradict dire predictions of adverse health consequences as a result of global warming. Further research for other states is indicated.
\end{abstract}

Keywords: Global warming, cancer, heart disease, death rates, Alabama

\section{Introduction}

Warm temperatures are thought to be associated with increased death rates $[\mathbf{1 , 2}]$. Indeed, the World Health Organization "estimates that since 2000 one million people have been killed directly or indirectly because of our warming planet" [3].

In a previous similar study, for Florida, cancer death rates and air temperature revealed an inverse relationship, where warmer temperatures were associated with lower death rates [4]. During the review process for that study, it was suggested to the author that other U.S. states be studied as a next step. Thus, Alabama was (alphabetically) selected for the present study. The present study differs from the Florida study in that the present study adds a second response variable-heart disease death rates-to capture death rates for the two typical top causes of death in the U.S. -cancer and heart disease. Since smoking is a factor in death rates, and since smoking rates can vary substantially between states (and perhaps to a lesser extent between counties within the same state), the one state-at-atime approach is used in an attempt to avoid between-state variation of smoking rates. As was used in the Florida study [4] and by others looking at health effects of temperature [5] an ecological design is used in the present study. Since land elevation has been shown to be related to death rates [6-8], it was also included in the Florida and present study as a second "dose" (predictor) variable.

\section{Methods}

One of the response variables in the present study was average age-adjusted cancer death rates (per 100,000) during 20062010 (the most recent years available at the time of the study for this variable), by county in Alabama, all ages, and all cancer sites [9] (Figure 1). The other response variable in this study was average age-adjusted heart disease death rates (per 100,000) during 2008-2010 (the most recent years available at the time of the study for this variable), also by county in Alabama, for all heart disease, all ages, both genders, white (non-Hispanic), data being spatially smoothed within the database [10] (Figure 2). Since death rates tend to differ by race, and since different races may be represented in greater percentages in different parts of a state (that also have different temperatures), one race was selected-that provided the greatest number of counties reporting data-the white (non-Hispanic) race-for both response variables.

One of the dose (predictor) variables in this study was average daily air temperature (in Fahrenheit) for 2006-2010, also by county in Alabama [11]. This variable was calculated by 
John Hart, Applied Scientific Reports 2015,

Age-Adjusted death rates for Alabama, 2006-2010 All cancer sites

White Non-Hispanic, both sexes

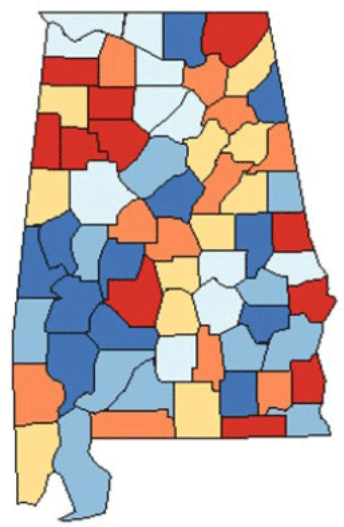

Figure 1. Cancer death rates in Alabama [9]

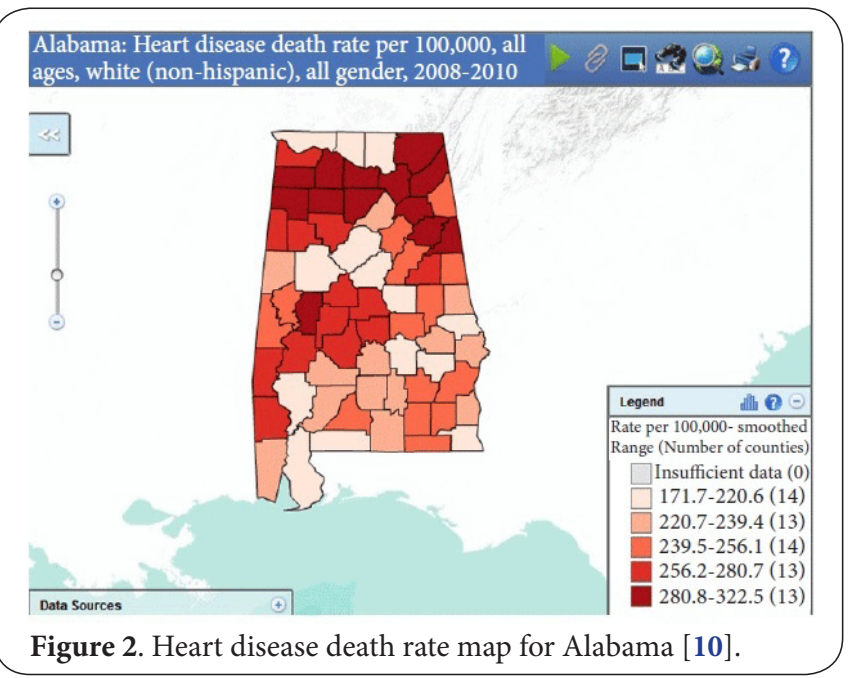

averaging the mean daily maximum and mean daily minimum temperatures by county. The resulting average of the mean minimum and mean maximum temperatures is now referred to simply as "temperature" for each county and was analyzed as a continuous variable. The other dose (predictor) variable in this study was county land elevation, from The National Map viewer [12]. This variable was obtained at the geographic center of each county using the Get Elevation option from a drop-down menu (example provided for Autauga County in Figure 3). Seven of the 67 Alabama counties showed their elevations, in this author's view as being noticeably off-center (geographically-speaking) using the Get Elevation method. Elevations for these seven counties were instead obtained by using a Spot Elevation tool provided by the database, at a point estimated by the author to be at the geographic center of the county. This variable is now referred to as "elevation" for each county and was also analyzed as a continuous variable. All 67 of Alabama's counties were included in the study.

Analysis consisted of inspecting the relationship between dose and response variables in scatter plots. No obvious nonlinear patterns were observed in these plots (Figures 4-7). Normal probability plots for the response variables indicated accepted normality (Figures 8 and 9). Thus, linear multiple regression was considered appropriate for these data to test the association between dose and response variables. The analysis was performed in Stata IC 12.1 (StataCorp, College Station, TX). The slight unequal variance observed in the scatter plots was addressed by using the "robust" command in Stata. The two regression models (cancer death rates and heart disease death rates) each included the same two predictors (elevation and temperature). In addition, and out of curiosity, the relationship between temperature and elevation was examined. Since their scatter plot (Figure 10) did not reveal an obvious nonlinear relationship, Pearson correlation was considered appropriate for these two variables (temperature and elevation). Two-tailed $p$-values less than or equal to the traditional

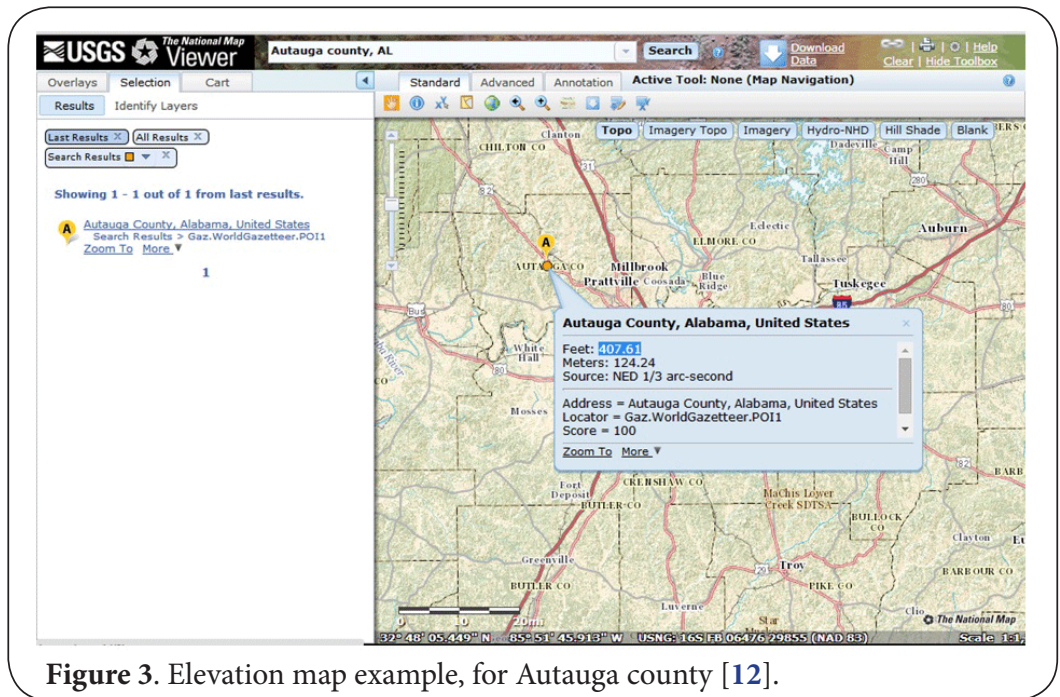


John Hart, Applied Scientific Reports 2015,

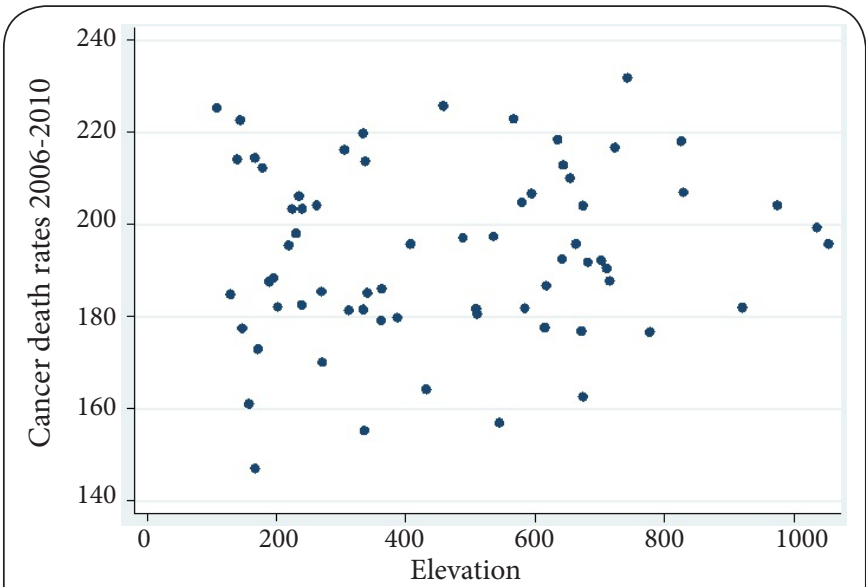

Figure 4. Scatter plot for cancer death rates and elevation.

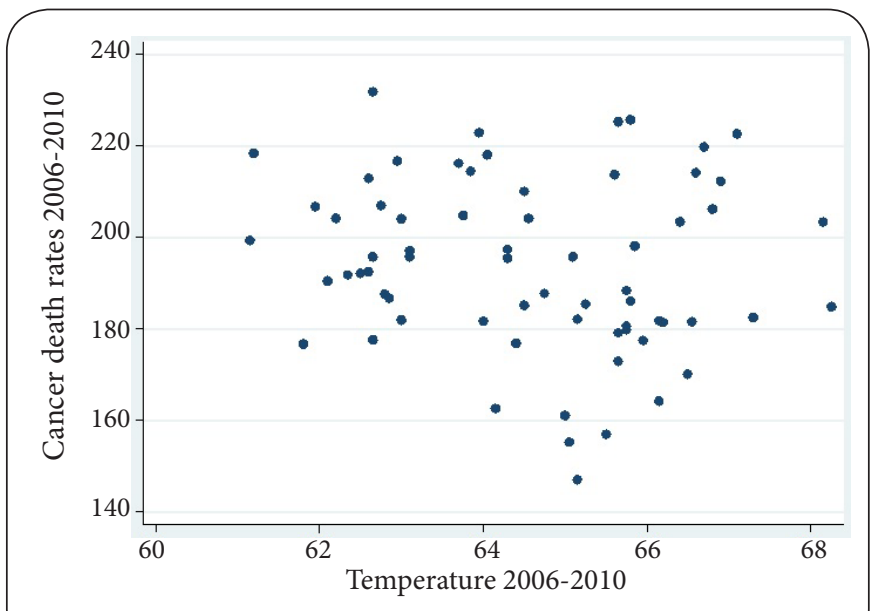

Figure 5. Scatter plot for cancer death rates and temperature.

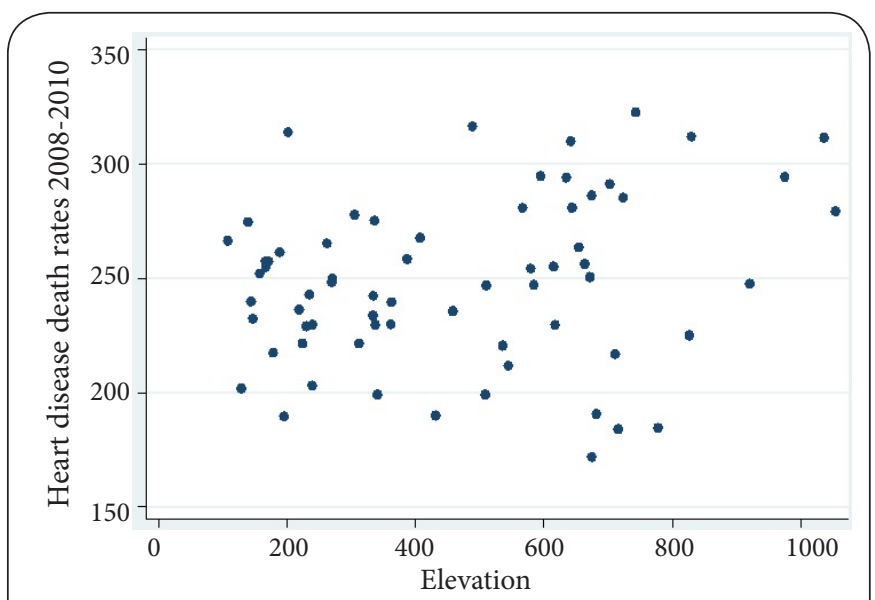

Figure 6. Scatter plot for heart disease death rates and elevation.

alpha level of 0.05 were considered statistically significant.

Results

Descriptive and summary statistics are provided in Table 1. In

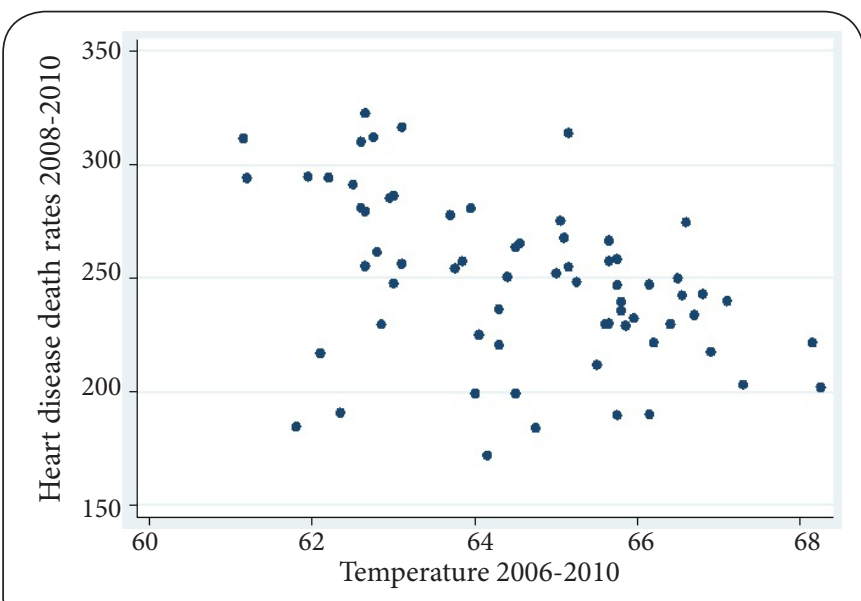

Figure 7. Scatter plot for heart disease death rates and temperature.

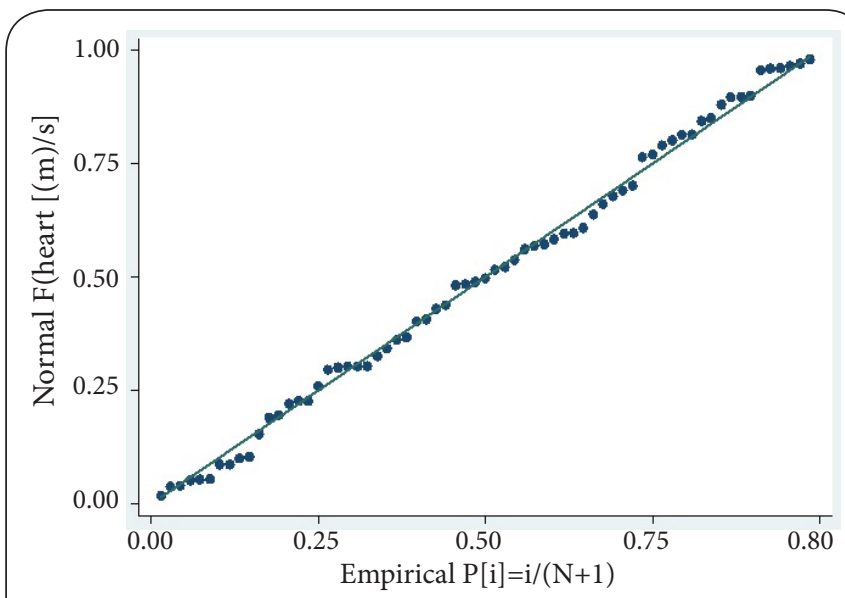

Figure 8. Normal probability plot for heart disease death rates.

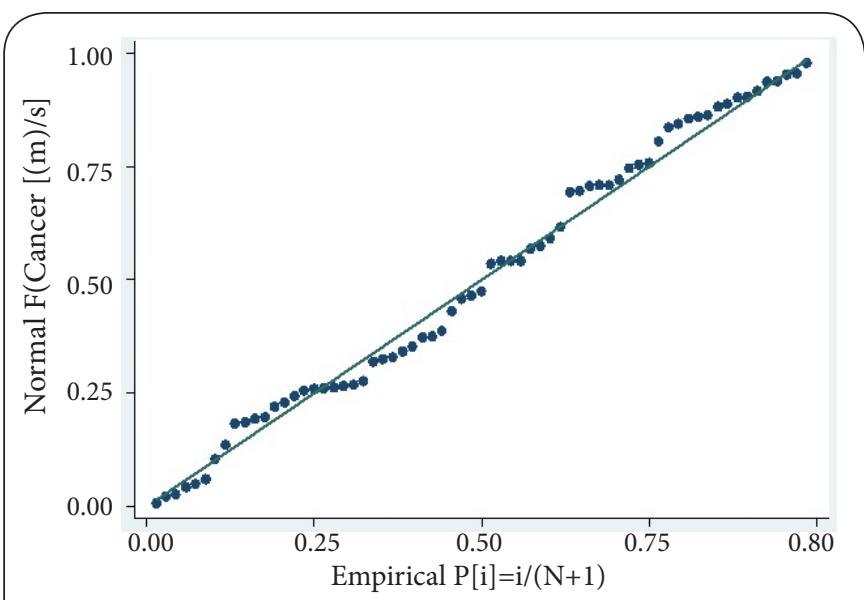

Figure 9. Normal probability plot for cancer death rates.

the cancer model, regression coefficients for predictors were not statistically significant ( $p>0.3$; Table 2 ), and the model Rsquared value also was small and not statistically significant (R-squared $=0.022, \mathrm{p}=0.4$ ). 
John Hart, Applied Scientific Reports 2015,

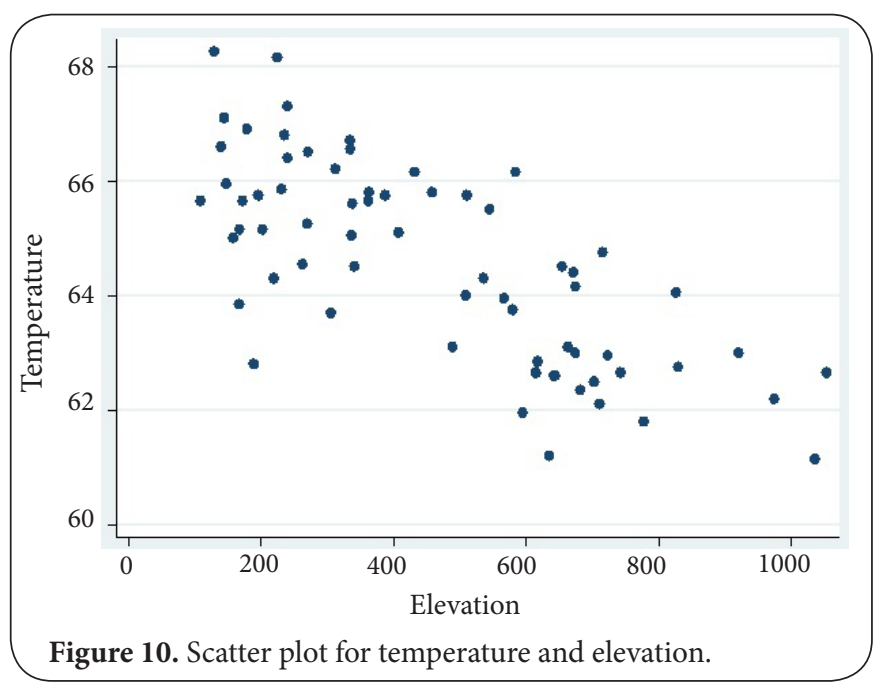

Table 1. Descriptive and summary statistics. County averages for heart disease death rates, air temperature, cancer death rates, and land elevation. Summary statistics are at the bottom of the table.

\begin{tabular}{lllll}
\hline County & Heart & Temperature & Cancer & Elevation \\
\hline Autauga & 267.7 & 65.10 & 195.7 & 407.61 \\
Baldwin & 201.8 & 68.25 & 184.8 & 128.71 \\
Barbour & 247.0 & 66.15 & 181.7 & 584.92 \\
Bibb & 265.2 & 64.55 & 204.1 & 262.9 \\
Blount & 229.5 & 62.85 & 186.6 & 617.65 \\
Bullock & 211.5 & 65.50 & 156.9 & 545.23 \\
Butler & 239.4 & 65.80 & 186.0 & 363.00 \\
Calhoun & 286.1 & 63.00 & 204.0 & 674.41 \\
Chambers & 225.0 & 64.05 & 218.1 & 826.53 \\
Cherokee & 255.1 & 62.65 & 177.6 & 615.00 \\
Chilton & 263.5 & 64.50 & 210.0 & 654.5 \\
Choctaw & 258.4 & 65.75 & 179.7 & 386.55 \\
Clarke & 189.9 & 66.15 & 164.2 & 431.62 \\
Clay & 279.1 & 62.65 & 195.7 & 1053.76 \\
Cleburne & 294.3 & 62.20 & 204.1 & 975.43 \\
Coffee & 249.9 & 66.50 & 170.0 & 271.24 \\
Colbert & 261.3 & 62.80 & 187.6 & 188.13 \\
Conecuh & 242.1 & 66.55 & 181.5 & 334.36 \\
Coosa & 220.6 & 64.30 & 197.3 & 535.82 \\
Covington & 229.7 & 66.40 & 203.4 & 240.35 \\
Crenshaw & 229.7 & 65.60 & 213.7 & 338.00 \\
Cullman & 310.0 & 62.60 & 192.5 & 642.41 \\
Dale & 242.8 & 66.80 & 206.2 & 235.00 \\
Dallas & 266.4 & 65.65 & 225.3 & 108.14 \\
DeKalb & 311.4 & 61.15 & 199.3 & 1036.51 \\
Elmore & 248.2 & 65.25 & 185.3 & 269.29 \\
Escambia & 217.4 & 66.90 & 212.2 & 179.00 \\
Etowah & 311.8 & 62.75 & 206.9 & 829.94 \\
Fayette & 257.2 & 63.85 & 214.4 & 166.21 \\
Franklin & 322.5 & 62.65 & 231.8 & 742.68 \\
Geneva & 239.9 & 67.10 & 222.6 & 143.97 \\
\hline
\end{tabular}

Continuations of Table 1.

\begin{tabular}{|c|c|c|c|c|}
\hline County & Heart & Temperature & Cancer & Elevation \\
\hline Greene & 251.9 & 65.00 & 161.0 & 157.17 \\
\hline Hale & 313.7 & 65.15 & 182.0 & 202.34 \\
\hline Henry & 233.7 & 66.70 & 219.8 & 334.18 \\
\hline Houston & 202.8 & 67.30 & 182.5 & 239.00 \\
\hline Jackson & 294.0 & 61.20 & 218.4 & 635.54 \\
\hline Jefferson & 199.1 & 64.00 & 181.6 & 509.07 \\
\hline Lamar & 277.7 & 63.70 & 216.1 & 305.19 \\
\hline Lauderdale & 190.5 & 62.35 & 191.7 & 682.43 \\
\hline Lawrence & 280.8 & 62.60 & 212.9 & 643.57 \\
\hline Lee & 184.0 & 64.75 & 187.7 & 715.5 \\
\hline Limestone & 216.7 & 62.10 & 190.4 & 710.85 \\
\hline Lowndes & 229.0 & 65.85 & 198.1 & 229.93 \\
\hline Macon & 229.8 & 65.65 & 179.1 & 362.00 \\
\hline Madison & 184.5 & 61.80 & 176.6 & 777.58 \\
\hline Marengo & 257.3 & 65.65 & 172.9 & 172.16 \\
\hline Marion & 316.3 & 63.10 & 197.0 & 489.48 \\
\hline Marshall & 294.6 & 61.95 & 206.7 & 595.26 \\
\hline Mobile & 221.4 & 68.15 & 203.3 & 223.78 \\
\hline Monroe & 221.4 & 66.20 & 181.3 & 312.04 \\
\hline Montgomery & 189.5 & 65.75 & 188.3 & 195.27 \\
\hline Morgan & 291.0 & 62.50 & 192.1 & 702.74 \\
\hline Perry & 275.2 & 65.05 & 155.2 & 335.86 \\
\hline Pickens & 236.2 & 64.30 & 195.4 & 218.46 \\
\hline Pike & 246.8 & 65.75 & 180.6 & 510.04 \\
\hline Randolph & 247.5 & 63.00 & 181.9 & 921.14 \\
\hline Russell & 235.6 & 65.80 & 225.7 & 458.06 \\
\hline Shelby & 171.7 & 64.15 & 162.5 & 674.44 \\
\hline St. Clair & 256.1 & 63.10 & 195.7 & 663.28 \\
\hline Sumter & 254.7 & 65.15 & 147.0 & 167.25 \\
\hline Talladega & 254.1 & 63.75 & 204.8 & 580.06 \\
\hline Tallapoosa & 250.5 & 64.40 & 176.8 & 672.00 \\
\hline Tuscaloosa & 199.1 & 64.50 & 185.1 & 340.54 \\
\hline Walker & 280.7 & 63.95 & 222.8 & 567.04 \\
\hline Washington & 274.5 & 66.60 & 214.1 & 139.3 \\
\hline Wilcox & 232.1 & 62.95 & 177.4 & 146.68 \\
\hline Winston & 285.0 & 62.95 & 216.7 & 724.04 \\
\hline $\mathrm{n}$ & 67 & 67 & 67 & 67 \\
\hline Mean & 248.6 & 64.6 & 193.7 & 464.2 \\
\hline SD & 36.2 & 1.7 & 15.9 & 249.5 \\
\hline Minimum & 171.7 & 61.2 & 147.0 & 108.1 \\
\hline Maximum & 322.5 & 68.3 & 231.8 & 1053.8 \\
\hline
\end{tabular}

The heart disease model revealed: a) statistical non-significance for elevation $(p=0.187)$, b) statistical significance for temperature $(p<0.001)$ with an inverse coefficient $(-11.9 ; 95 \%$ confidence interval=-17.7 to -6.1 ; Table 2 ), and c) a statistically significant model R-squared value of $0.203(p=0.0003)$. 
John Hart, Applied Scientific Reports 2015,

Table 2. Regression statistics for the two models (cancer death rates and heart disease death rates).

\begin{tabular}{lllll}
\hline \multicolumn{5}{c}{ Cancer } \\
\hline Predictor & Coefficient & $\mathbf{p}$ & $\mathbf{9 5 \%}$ CI & VIF \\
\hline Elevation & 0.0 & 0.994 & -0.03 to 0.03 & 2.2 \\
Temperature & -1.6 & 0.394 & -5.3 to 2.1 & 2.2 \\
\hline \multicolumn{5}{c}{ Heart disease } \\
\hline Predictor & Coefficient & $\mathbf{p}$ & $\mathbf{9 5 \%}$ CI & VIF \\
\hline Elevation & -0.0 & 0.187 & -0.07 to 0.01 & 2.2 \\
Temperature & $\mathbf{- 1 1 . 9}$ & $<\mathbf{0 . 0 0 1}$ & $\mathbf{- 1 7 . 7}$ to $\mathbf{- 6 . 1}$ & $\mathbf{2 . 2}$ \\
\hline
\end{tabular}

Coefficient=Regression coefficient; $\mathrm{p}=\mathrm{p}$-value for the regression coefficient; $\mathrm{CI}=$ Confidence interval for the regression coefficient; $\mathrm{VIF}=$ Variance inflation factor; Bold=Statistically significant association

Although the correlation between temperature and elevation was fairly strong and statistically significant (and inverse; $r=-$ $0.738, p<0.0001)$, collinearity was not a problem in either of the regression models, where the variance inflation factor was 2.2 for both predictors in both models.

\section{Discussion}

Warmer counties in this study were found to be not associated with higher death rates in either model. Indeed, the inverse relationship between temperature and heart disease death rates in this study indicates a beneficial association (between warmer air and heart disease death rates). This indicates that as temperature increases, heart disease death rates tend to decrease. This relationship, represented by the regression coefficient of -11.9 indicates that as temperature increases by 1 degree, heart disease death rates on average would be expected to decrease by approximately 12 per 100,000 persons within the temperature range of this study (61.2 to 68.3 degrees F; Table 1). These (lack of adverse) findings in warmer counties are: a) not consistent with global warming predictions of doom and gloom, [13] and b) consistent with a previous report that indicated a beneficial association between warmer temperatures and decreased mortality [14]. It remains unknown why a previous study on cancer death rates and air temperature showed a statistically significant relationship between higher air temperatures and lower cancer deaths [4] while the present study did not show any statistically significant relationship. One possibility is that in the Florida study there was a wider range of temperatures, 67.6 degrees $F$ to 76.6 degrees $F$, versus 61.2 degrees $F$ to 68.3 degrees $F$ in the present study. In other words there was a difference of 9.0 degrees $F$ in the Florida study (between lowest and highest temperatures) versus a difference of 7.1 degrees $\mathrm{F}$ in the present study (between lowest and highest temperatures). The difference of the difference is just under 2 degrees $F$, which may or may not be related to the difference in the statistical findings. However, the two studies do have one thing in common here: neither showed a statistically significant association between higher air temperatures and higher cancer death rates. It is also unknown why heart disease death rates showed a statistically significant decrease in higher air temperature counties while no statistical significance was shown for cancer death rates. It could be that air temperature has a greater affect on heart disease death rates versus cancer death rates.

The correlation between elevation and temperature was inverse, and in this study, fairly strong. This means that as land elevation increased, air temperature tended to decrease, as expected.

A limitation to the study is that its (ecological) design means that individual exposures are unknown. On the other hand, this design: a) is also a strength in this study inasmuch as it provides a sample that essentially consists of an entire state, and $b$ ) is apparently not considered a limitation by others who have used this design in a similar study [5] as this writer did not see in their paper that they mentioned their ecological design as being a limitation for their study. Another limitation to this preliminary study is that other factors were not included, such as access to health care and income by county.

\section{Conclusion}

This study did not reveal an adverse association between warmer air temperatures and death rates for cancer or heart disease. Indeed, warmer temperatures were related to lower death rates for heart disease. Further study on "global warming" and death rates for other states is indicated.

\section{Competing interests}

The author declares that he has no competing interests.

\section{Publication history}

Editor: James A Radosevich, University of Illinois at Chicago, USA. Received: 27-Aug-2014 Final Revised: 27-Jan-2015

Accepted: 10-Feb-2015 Published: 17-Feb-2015

\section{References}

1. Longstreth J. Anticipated public health consequences of global climate change. Environ Health Perspect. 1991; 96:139-44. | Article | PubMed Abstract | PubMed Full Text

2. Zanobettia A, O'Neill MS, Gronlund, CJ and Schwartz JD. Summer temperature variability and long-term survival among elderly people with chronic disease. Proceedings of the National Academy of Sciences 2012; 1097:6608-6613. | Article

3. Markey EJ. Global warming. 2014. | Website

4. Hart J. Association between air temperature and cancer death rates in Florida: An ecological study. Dose-Response. I Website

5. Braga AL, Zanobetti A and Schwartz J. The effect of weather on respiratory and cardiovascular deaths in 12 U.S. cities. Environ Health Perspect. 2002; 110:859-63. | Article | PubMed Abstract | PubMed Full $\underline{\text { Text }}$

6. Jagger J. Natural background radiation and cancer death in Rocky Mountain states and Gulf Coast states. Health Phys. 1998; 75:428-30. I Article | PubMed

7. Hart J and Hyun S. Cancer mortality, state mean elevations, and other 
John Hart, Applied Scientific Reports 2015,

http://www.hoajonline.com/journals/pdf/2054-9903-2-1.pdf

selected predictors. Dose Response. 2012; 10:58-65. | Article | PubMed Abstract I PubMed Full Text

8. Hart J. Heart disease death rates in low versus high land elevation counties in the U.S. Dose-Response. | Website

9. National Cancer Institute ( $\mathrm{NCl}$ ). Age-adjusted death rates for Alabama, 2006-2010 all cancer sites. 2014. | Website

10. Centers for Disease Control and Prevention (CDC). Intereactive atlas of heart disease and stroke tables. Alabama county statistics. 2014. Website

11. Centers for Disease Control and Prevention (CDC). North American land data assimilation daily air temperature and heat index. 2014.

12. U.S. Geological Survey (USGS). The National Map viewer. 2014. | Website

13. Hajat $S$, Vardoulakis $S$, Heaviside $C$ and Eggen B. Climate change effects on human health: projections of temperature-related mortality for the UK during the 2020s, 2050s and 2080s. J Epidemiol Community Health. 2014; 68:641-8. | Article | PubMed

14. Idso CD, Idso SB, Carter RM and Singer FS. Nongovernmental International Panel on Climate Change. Climate Change Reconsidered II. Chapter 7: Human health. 2014. I Pdf

\section{Citation:}

Hart J. Association between air temperature and deaths due to cancer and heart disease in Alabama. Appl Sci Rep. 2015; 2:1.

http://dx.doi.org/10.7243/2054-9903-2-1 